\title{
Adapting to Climate Change in the Severn Estuary Area: The Corporate Response by Local Government
}

\author{
Dr Rhoda. C. Ballinger, School of Earth and Ocean Sciences, Cardiff University, ballingerrc@cf.ac.uk \\ DrWendy Dodds, WWF Cymru, wdodds@wwf.org.uk
}

\begin{abstract}
Adapting to climate change is a major challenge for local governments across Europe. This is particularly true for the local governments bordering the dynamic Severn Estuary. Like elsewhere in Europe, the multiple local authorities bordering the Severn, have many functions and are in a unique position to prepare for, and adapt to, anticipated climate change impacts. This paper summarises the results of a Severn Estuary Planning Review. This evaluated local government corporate responses to climate change and reviewed related policies in the development plans of the planning bodies around the estuary. The study revealed areas of policy coherence and divergence. Despite all the local governments having signed up to national political declarations on climate change and having devised or being in the process of devising climate change strategies, the focus remains on mitigation. The limited reference to shoreline management and Integrated Coastal Zone Management poses obstacles to coordinated action, much needed on an estuary divided by administrative borders and institutional barriers. These findings suggest a need for further policy guidance to support local policy development. Whilst presenting examples of good practice, relevant to local governments elsewhere, the stocktaking procedure also has potential for application elsewhere.
\end{abstract}

Keywords: Severn Estuary, local government, climate change, adaptation, planning policy.

\section{Introduction}

It is widely recognised that the effects of climate change in Europe are significant, with the European Commission recently having stated that climate change, "will heavily affect Europe's natural environment and nearly all sections of society and the economy" (EC, 2007, pg. 4). Coastal locations are likely to be at considerable risk, as existing coastal hazards may be exacerbated by climate change (McInnes, 2009). On the Severn Estuary, where extensive coastal defences have been constructed since Roman Times, this is particularly true. This low lying and extensive estuary $\left(557 \mathrm{~km}^{2}\right)$, with the second highest tidal range in the world, is not only home to many urban and more rural coastal communities, major industries, ports and power stations, but also supports species of nationally and internationally important migrant wildfowl and waders (SEP, 2001). Under recent climate projections, UKCP09 ${ }^{1}$ predicts relative sea level rise around Wales to be $15 \mathrm{~cm}$ by the $2040 \mathrm{~s}$ and $36 \mathrm{~cm}$ by the 2080s (medium emission scenarios: WAG, 2009), suggesting that much of the Severn Estuary, its communities and environments are vulnerable.

The Severn Estuary is not unique: given the low lying nature of much of the European coast, adapting to climate change and particularly sea level rise, is a major challenge across the continent. Local governments, with their wide range of responsibilities, lie at the forefront of

\footnotetext{
1 The UK Climate Projections, published $18^{\text {th }}$ June 2009, http://ukclimateprojections.defra.gov.uk
} 
adaptation, 'anticipating the adverse effects of climate change and taking appropriate action to percent or minimise the damage they can cause" (EC, 2008, pg. 7). In this context, the Interreg IVB IMCORE project (www.imcore.eu) is bringing together local government and academic partners from sites across North West Europe to enhance local capacity for coastal climate change adaptation. As part of this project an IMCORE Severn Estuary Planning Review (2009/10) was undertaken to inform the development of IMCORE guidelines for climate change adaptation for the Severn, a cross-border estuary between England and Wales. Planning policy provides an indication of both current and future development and aims to "create a positive framework for action on climate change" (DCLG, 2008, pg. 4). Alongside this, Local Planning Authorities (LPAs) share responsibility for safeguarding people and property from risk, making them central to climate change adaptation. Consequently, the IMCORE project is focusing on the critical role of these bodies in preparing for and adapting to climate change on the Severn Estuary.

This paper presents an overview of the first phase of the IMCORE Severn Estuary Planning Review. This examined how local government is actively incorporating climate change into its working practices, focusing specifically on how planning bodies are embedding climate change-related considerations into their policies and associated actions. After an outline of the research methodology, the paper outlines the key results and conclusions of the review.

\section{Methodology}

To examine climate change-related planning policy in the Severn Estuary area, an extensive review of development plans around the estuary was undertaken, along with an assessment of corporate responses to climate change by local government (Table 1). The latter involved a content analysis of dedicated climate change strategies, being produced in response to the United Kingdom Government's climate change programme (DETR, 2000). The planning policy survey reviewed policies within the development plans of fourteen LPAs, two County Councils, one National Park, two Regional Planning Bodies and Welsh Assembly Government; encompassing in total, twenty planning bodies. In light of changes to the Town and County Planning System in England and Wales under the Planning Compulsory Planning Purchase Act 2004, there is a period of transition as LPAs replace existing, adopted plans with new documents. In England and Wales, separate, parallel systems require planning bodies to create integrated policies for the development and use of land under this new legislation. In England this takes the form of Local Development Frameworks (LDFs) (DCLG, 2008) and, in Wales, Local Development Plans (LDP). Whilst many LDPs and LDFs are in draft format, at varying stages of preparation, it was considered that these plans provide strong indication of likely future policy content. Consequently, the stocktake included both adopted (21) and emerging (12) planning documents.

The auditing process built on previous research, which 'read' plans for their sustainability (for example, Bruff and Wood, 1995; Counsell, 1999; and Hales, 2000) and coastal content (for example, Jemmett, 1995; Taussik, 1996; and Ballinger et al., 1999). A qualitative content analysis was developed to assess policies within the planning documents.

In summary, the stocktake reviewed three, overarching policy themes (climate change, flood and coastal erosion risk management and estuary management) and associated subcategories (Table 1). Individual policies were assessed in terms of their policy occurrence, policy content and geographical coverage, thus enabling patterns of policy coherence and 
divergence around the estuary to be determined. In terms of policy occurrence, the survey noted the presence or absence of relevant policies within different plan types and LPAs, as well as investigating variations between adopted and emerging plans. Policy content included an examination into the level of detail, direction and scope of each relevant policy as well as analysing specific issues, stipulations and actions associated with each policy, noting variability between plan types and authorities around the estuary.

\begin{tabular}{|c|c|}
\hline Policy themes & Sub-categories \\
\hline Climate Change & $\begin{array}{ll} & \text { Mitigation (carbon management \& other) } \\
\square & \text { Adaptation }\end{array}$ \\
\hline $\begin{array}{l}\text { Flood and Coastal Erosion Risk } \\
\text { Management }\end{array}$ & \begin{tabular}{|ll}
$\square$ & Development and the Coastal Zone \\
$\square$ & Development in Flood Risk Areas \& \\
$\square$ & Development Exacerbating Flooding \\
& Development and Coastal Erosion \\
& Reference to Shoreline Management Plans
\end{tabular} \\
\hline Estuary Management & $\begin{array}{ll}\square & \text { Reference to Severn Estuary } \\
& \text { Reference to Severn Estuary Strategy \&/or } \\
& \text { other estuary wide initiatives }\end{array}$ \\
\hline
\end{tabular}

Table 1: Stocktake policy themes and associated sub-categories

\section{Results}

\subsection{Local Authority Climate Change Strategies}

The research identified that all the local authorities around the estuary have signed up voluntarily to high-level strategic political declarations on climate change in England (The Nottingham Declaration on Climate Change: 2000) and Wales (The Welsh Declaration on Climate Change and Energy Efficiency, 2006). Whilst this might suggest full political engagement by local government on climate change, the review of local authority, dedicated climate change strategies around the estuary, revealed that only half (7) of the local authorities had developed such a strategy at the time of the survey. These included the earliest identified strategy, developed by Bristol City Council in 2004 to the most recently published strategies of Gloucester City Council and West Somerset District Council in 2008.

Content analysis revealed a clear emphasis on mitigation and energy-related targets, reflecting the focus of the English and Welsh declarations, noted above, as well as the need to contribute to central government domestic targets on carbon dioxide emissions reduction ${ }^{2}$. In addition to energy and renewable energy aspects, there were other common themes within the strategies, notably related to travel and transport; housing and buildings; waste and water. However, even though the national declarations commit authorities to climate change adaptation, only 3 of the strategies (43\%) contained dedicated sections or chapters addressing climate change adaptation, raising issues as to the adequacy of climate change adaptation measures being taken by Severn-side authorities.

\footnotetext{
2 http://www.energysavingtrust.org.uk/Easy-ways-to-stop-wasting-energy/Energy-saving-grants-and-offers/Carbon-cuts-getserious-with-CERT
} 


\subsection{Planning Policy Results}

This section provides a brief overview of the findings of the review of planning policy around the estuary, focusing in turn on each of the key themes and sub-categories listed in Table 1.

\subsubsection{Climate Change Policy}

Not unsurprisingly, given the timing of the preparation and adoption of many of the adopted plans, prior to the publication of the UK's climate change programme in 2000, most (13 out of 21: $62 \%$ ) made no explicit reference to climate change within their policies. Of those that did, $8(38 \%)$ focused on mitigation, including energy conservation, energy generation and energy efficient development, reflecting the political commitments and climate change strategy foci, noted above. In contrast, explicit climate change policies addressing both mitigation and adaptation occurred in some of the draft plans. Overall, there was a significant increase in explicit climate change policies within emerging plans, signalling a recognition by planning bodies that climate change is an issue requiring a dedicated, policy response. Of the 8 LPAs with draft climate change-related policies, objectives and measures, none had previously had climate change policies within their adopted plans.

On detailed examination of relevant policies, it was clear that there was a mixture of generalised policies to others in which climate change was considered in more detail. However, a number of key themes relating to climate change mitigation, adaptation and associated flooding were identified. With respect to mitigation, sub-themes included the provision and promotion of sustainable public transport as well as energy efficiency and generation matters. Other topics included vulnerability assessments of communities and ecosystems, the use of green infrastructure to limit the heating of the urban environment and increase resource efficiency, in addition to waste and pollution minimisation. Whilst adaptation only featured in less than half of the policies and measures, there were some farsighted policies concerned with sustainable design and construction including future proofing new development, the setting higher design standards for construction and requirements for Sustainable Urban Drainage Systems. Finally, climate change policies, referring to flooding, included reference to the need for flood risk reduction and management, were commonplace. This finding reinforces the prominence of this issue within planning and highlights its potential notoriety as a climate change issue and anticipated impact on the Severn Estuary.

\subsubsection{Flood and Coastal Erosion Risk Management Policy}

As flood risk is a 'material consideration' under the Town and Country Planning System and LPAs can guide and control the location of development to reduce flood risk, it was not surprising that there was a strong presence of flood risk-related policies around the estuary within both adopted and emerging plans. Indeed, the implications of coastal flooding and erosion on development, and the exacerbation of natural processes by inappropriate development traditionally have been major concerns along much of the coast of England and Wales (Lee, 1993) and on the Severn Estuary where thousands rely on artificial defences to protect coastal land and property, and extensive lowlands lie more than three metres below the highest tides (Severn Estuary Strategy/Environment Agency, 1997). Of the 21 adopted plans, 18 contained policies addressing development and flood risk (86\%). Within the emerging planning documents, $8(67 \%)$ had development and flood risk-related policies. These numbers reinforce the significance of flood risk for LPAs around the estuary. However, 
within a couple of authorities, emerging plans had dropped explicit development and flood risk-related policies, supplanting these with more generic climate change policies embracing elements of flood risk. In most cases, policies relating to flood risk contained detailed stipulations concerning future development in flood risk areas. However, a small number of plans only contained limited detail within their policies and supporting text. Overall, the policies relating to flood risk within adopted plans tended to refer to negative impacts, with policies precluding development in areas at flood risk, suggesting mitigation measures for development in flood risk areas, as well as outlining requirements for Flood Risk Assessments and avoiding surface water run-off issues.

The detailed content of development and flood risk-related policies was reviewed within 8 emerging plans including the draft RSS for the South West. Overall, policies were briefer than in the corresponding, adopted plans. This trend may reflect the recent requirement for LPAs not repeat national planning guidance. Emerging planning policies related to 'development and flood risk' included ones outlining a need for a sequential approach to flood risk management as well as others referring to regeneration issues, design aspects of future developments to increase resilience to flooding, and requirements for Sustainable Urban Drainage Systems. At a more strategic level, the policies within the South West Regional Spatial Strategy and the Wales Spatial Plan suggest inconsistency in strategic estuary-wide guidance. Policy F1 Flood Risk within the draft RSS for the South West (2006) contains various, interesting aspects, namely, the relocation of existing development away from areas of coastal risk and the need to identify areas for management realignment. The Wales Spatial Plan (2008 Update), in contrast, does not refer to flooding or contain advice on flood risk management for Welsh Severn Estuary LPAs.

In contrast to the large number of policies referring to development and flood risk, few policies relating to 'development and coastal defence / erosion' were found within either the adopted or emerging plans. As no 'development and coastal erosion' policies were found within the emerging plans, it can be inferred that coastal erosion is not a significant policy priority. It is, however, unclear if planning bodies have undertaken coastal erosion risk mapping / assessments to determine if this is actually the case.

Policies relating to 'development and the coastal zone' were reviewed as part of the Flood and Coastal Erosion Risk Management theme: it was deemed that these would provide an overview of the extent to which LPAs consider the specific character and nature of coastal areas within policy development. Within the adopted plans, a number of coastal zone policies were identified (13 thirteen out of $21: 62 \%$ ). This high take-up may reflect the issuing of specific national planning policy guidance on coastal planning issued in the 1990s, following the influential House of Commons Environment Committee Select Committee report Coastal zone protection and planning (1992). In stark contrast, there were no discrete coastal zone policies identified within any emerging, draft plans.

Similarly, references to the Severn Estuary Shoreline Management Plan (SMP), a management plan designed to deliver strategic management of flood and erosion risk, were only located in 7 adopted and draft planning documents and only in 1 of the 4 Welsh plans. Due to the critical role of SMPs within Defra's and the Welsh Assembly Government's Flood and Coastal Erosion Risk Management delivery framework for England and Wales, this 'dropping off' of coastal and SMP-related policies is of concern. 


\subsubsection{Estuary Management Policy}

Not unlike the dearth of coastal zone policies, the stocktake also found scarce reference to the Severn Estuary and its unique characteristics and needs. Where the estuary was discussed within planning documents, this was generally within either nature conservationrelated policies or associated, supporting text, presumably reflecting traditional concerns of planning authorities around the estuary (Ballinger et al, 1999) and elsewhere (Taussik, 1995) as well as local authorities' role as Relevant Authorities for the Severn Estuary Special Area of Conservation. Similarly, reference to the Severn Estuary Strategy (SES), produced in 2001 by the Severn Estuary Partnership to provide an overarching, strategic management framework for the estuary and to provide for an integrated, cooperative approach, was only noted in 4 adopted plans, a similar uptake to that reported by Jemmett for the Dee Estuary in the mid 1990s (Jemmett, 1995). However on the Severn, 2 adopted plans had approved the Strategy as Supplementary Planning Guidance, enabling a better understanding of the estuary within the planning process and making the holistic estuary management approach of the Strategy, a material consideration in determining planning applications. Unfortunately, in the emerging, draft plans there is no reference to the Severn Estuary Strategy. Although the reasons for this decline are unknown, it is suggested that the dearth of policies may be partly explained by a short-term institutional memory and decreasing prominence of estuarywide networking by LPAs as well as the lack of an update of the voluntary, non-statutory 2001 Strategy, which has been superseded by the requirements of statutory plans and strategies, including the Management Scheme for the Severn Estuary European Marine Site and the Severn River Basin Management Plan (Ballinger and Stojanovic, 2010).

\section{Discussion and conclusion}

This research, focusing on climate change policy within local government climate change strategies and development plan policies around the Severn Estuary, revealed some interesting areas of both policy coherence and divergence. In the absence of specific national planning policy guidance on climate change adaptation, the variability of policies was not unanticipated. However, there were anomalies between local policy approaches, which cannot be explained by local coastal characteristics alone.

Although the UK government highlighted the leading role expected of local authorities in tackling climate change (DETR, 2000) within its climate change programme (DETR, 2000) over a decade ago and this research has indentified a strong commitment to climate change mitigation by all the Severn-side local government bodies, few emerging, draft plans have, as yet, begun to address adaptation. This might be expected though, given the recognition that adaptation is likely to be a long and continuous process (Commission of European Communities 2009). In relation to allied policies, the review revealed a prevalence of 'development and flood risk' policies in both adopted and emerging plans, whilst only a small number of coastal zone-related policies in adopted plans. Emerging plans suggest a further 'dropping off' of these policies along with references to both the Severn Estuary Strategy and the SMP, raising concerns as to the profile of coastal planning by Severn Estuary LPAs. Such findings suggest a need for planning bodies to recognise more fully the coastal nature of their areas. Any sense of estuary cohesion and awareness by planners, however, is a challenge given the fragmentation of local government around the estuary. 
Coastal communities around the Severn Estuary are likely to be at the forefront of dealing with expected climate change impacts, particularly sea level rise. Whilst this study has provided evidence to show that planning bodies are beginning to address climate change, there is still a need for LPAs to mainstream adaptation into all relevant polices and plans. As suggested by Franzen and Orlova (2008) and UNFCCC (2009) respectively, there is a need for adaptation to be more effectively integrated into the coordinated and consistent activities of national and regional government and local action, as well as being supported by a planned response and associated proactive measures. On the Severn this means trying respond to adaptation in a better planned and coordinated manner to avoid short term-ism and ineffective use of resources. Terrestrial spatial planning is, however, only one function of local authorities. Given the cross-cutting nature of climate change, adaptation requires horizontal integration within local government structures and across administrative boundaries. The Severn Estuary's governance arrangements are complex with numerous existing and emerging estuary management plans and strategies under development and revision (Ballinger and Stojanovic, 2010). Greater interlinkages should be made between the planning system and these plans, especially shoreline management plans, given the latter's important role in aiding coastal resilience.

Whilst these results should be of interest and provide good practice examples to local government in coastal areas facing similar climate change impacts and vulnerabilities, it is hoped that the auditing system used here may be adaptable to other coastal situations and plans. Certainly, on the Severn it has provided a useful method for establishing a bench mark on climate change adaptation policy against which future reviews can be compared.

\section{References}

Ballinger, R.C., Myatt, L., Scott, D. and Potts, J.S. (1999) Severn Estuary development plan analysis: 1999. University of Cardiff. Report for the Environment Agency.

Ballinger, R.C. and Stojanovic, T.S. (2010) Policy development and the estuary environment: a Severn Estuary case study, Marine Pollution Bulletin, 6(1-3), The Severn Estuary and Bristol Channel: a 25 year critical review, $132-145$.

Bruff, G. and Wood A. (1995) Sustainable development in English metropolitan district authorities: an investigation using unitary development plans. Sustainable Development Vol. 3, pp. 9-19.

Commission of European Communities (2009) White Paper Adapting to Climate Change: Towards a European Framework for Action. COMM (2009) 147 Final.

Franzen, I. and Orlova, S. (2008) Climate change: building adaptive capacity of local and regional authorities. The Council of Local and Regional Authorities. CG(14)33REP. 13 February 2008.

Counsell, D. (1999) Sustainable development and structure plans in England and Wales: operationalizing the themes and principles Journal of Environmental Planning and Management Vol. 42 No. 1, pp. 45-61.

Department of Communities and Local Government (2008) Planning Policy Statement 12: creating strong safe and prosperous communities through Local Spatial Planning. June 2008. London: TSO. 
Department of Environment, Transport and the Regions (2000) Climate Change: The UK Programme. London: TSO.

European Commission (2008) EU action against climate change: Adapting to climate change. Luxembourg: Office for Official Publications of the European Communities.

Hales, R. (2000) Land use development planning and the notion of sustainable development: exploring constraint and facilitation within the English planning system. Journal of Environmental Planning and Management Vol. 43 pp. 99-121.

House of Commons Environment Select Committee 1992 Coastal zone protection and planning, Second Report, Volume 1, Sessions 1991 - 92, HMSO, London.

Jemmett, A. (1995). Integrated coastal zone management: lessons from the Dee estuary, UK, in: Healy, M.G. and Doody, J.P. (1995). Directions in European coastal management. pp. 447-450.

Lee, M (1993) Coastal Planning and Management; a review, A report for the Department of the Environment by Rendel Geotechnics, HMSO

McInnes, R.G. (2009) Coastal Risk Management: A Non-Technical Guide. Isle of Wight: Isle of Wight Centre for Coastal Environment.

Severn Estuary Partnership (2001) Strategy for the Severn Estuary.

Severn Estuary Strategy/Environment Agency (1997) Severn Estuary Joint Issues Report, Severn Estuary Strategy/Environment Agency, 173pp.

Taussik, J. (1996) Development plans and the coastal zone. Town Planning Review. Vol.67. No. 4, pp. 397-420.

Taussik, J (1995) The contribution of development plans to coastal policy with particular reference to nature conservation, Directions in European Coastal Management, Healy and Doody JP (Eds.), Samara Publishing Ltd., Cardigan.

United Nations Framework Convention on Climate Change (2009) Fact sheet: The need for adaptation. UNFCCC; September 2009.

Welsh Assembly Government (2009) Climate Change: its impacts for Wales. November 2009.

\section{Acknowledgements}

This research was supported by the European Regional Development Fund's Interreg IVB IMCORE project (www.imcore.eu). 